\title{
The combination of three faecal parasitological methods to improve the diagnosis of schistosomiasis mansoni in a low endemic setting in the state of Ceará, Brazil
}

\author{
Marta Cristhiany Cunha Pinheiro, ${ }^{1,+}$, Teiliane Rodrigues Carneiro², Ana Lúcia de Paula Hanemann², \\ Sara Menezes de Oliveira ${ }^{2}$, Fernando Schemelzer Moraes Bezerra ${ }^{1,2,3}$ \\ Departamento de Análises Clínicas e Toxicológicas ${ }^{2}$ Departamento de Patologia e Medicina Legal ${ }^{3}$ Departamento de Saúde Comuni- \\ tária, Faculdade de Medicina, Universidade Federal do Ceará, Fortaleza, CE, Brasil
}

Laboratory diagnosis of intestinal schistosomiasis mansoni can be accomplished through various methods of stool examination to detect parasites, ranging from the most classic tests (Kato-Katz) to several methods that are still undergoing validation. This study was conducted to assess two new parasite identification methods for diagnosing schistosomiasis mansoni in residents of a low endemic area in the municipality of Maranguape, in the state of Ceará, Brazil using the Kato-Katz method as a reference and serology (enzyme-linked immunosorbent assay) for the screening of patients. The Kato-Katz, the saline gradient method and the Helmintex ${ }^{\circledR}$ method parasite identification methods were employed only in subjects who exhibited positive serologic tests. The test results were then analysed and treatment of positive individuals was subsequently performed. After comparing the test results, we observed that the saline gradient method and the Helmintex ${ }^{\circledR}$ method were more effective in diagnosing schistosomiasis mansoni in the study area compared with the Kato-Katz method.

Key words: diagnosis - Schistosoma mansoni - Kato-Katz - ELISA - saline gradient - Helmintex ${ }^{\circledR}$

Schistosomiasis is endemic in 76 countries and territories around the world. In mid-2003, it was estimated that 779 million people were at risk for schistosomiasis and that 207 million people were infected (WHO 2008). Laboratory diagnosis of this parasitic disease can be performed using either direct methods, based on the identification of parasite eggs in the patient's faeces or tissues (Rabello et al. 2008) or indirect methods, which include the enzyme-linked immunosorbent assay (ELISA) method for detecting circulating antigens and polymerase chain reaction (PCR)-based methods. Because the ELISA technique allows for automation and provides quantitative results, this method has been shown to be best suited for application in population studies (Oliveira et al. 2003). A known limitation of this parasitological detection method is its lack of sensitivity, particularly in areas of low endemicity and in individuals infected with low parasite loads. According to data from the Schistosomiasis Control Program, the state of Ceará $(\mathrm{CE})$ is characterised as a low prevalence area. The locality showing the highest rates of positivity for schistosomiasis in CE is Planalto do Cajueiro in the municipality of Maranguape (the target subject area of this study), where there was a prevalence of $8.53 \%$ detected in 2006 and $13.76 \%$ in 2007; however, in the last five years, this area has been considered a low endemic area. Examination of a larger quantity of faeces is necessary to overcome the low sensitivity of the Kato-Katz method because the results of control programs based on the

+ Corresponding author: martacristhiany@yahoo.com.br Received 13 February 2012

Accepted 1 June 2012 analysis of a single Kato-Katz slide have been extremely contested in areas of low endemicity, as is the case for Brazil (Enk et al. 2008). In light of the factors noted above, there has been growing interest in the development of new methods, such as the Helmintex ${ }^{\circledR}$ method and the saline gradient method. The Helmintex ${ }^{\circledR}$ method is primarily used to identify Schistosoma mansoni eggs in large quantities of faeces (30 g). The saline gradient method involves a simple device based on a salinity gradient used for the purification of eggs, which are then detected via microscopic examination. Egg detection systems with higher sensitivity are desirable methods for achieving a definitive diagnosis and for use in the assessment of indirect diagnostic methods (Teixeira et al. 2007). Therefore, the objective of this study was to compare these two new parasite identification methods for the diagnosis of schistosomiasis mansoni in residents from a low endemic area in the municipality of Maranguape, using the Kato-Katz method for comparison and a serological ELISA method to screen patients.

\section{SUBJECTS, MATERIALS AND METHODS}

This investigation consisted a prospective crosssectional intervention study (patients treatment) carried out in the locality of Planalto do Cajueiro. This locality is a small community with 903 inhabitants distributed across five urban blocks, according to a survey conducted by the city hall. The area is surrounded by two streams and Biomphalaria straminea is the intermediate host of schistosomiasis. The study period was from May 2009-March 2010.

ELISA method - For ELISA testing, venous blood was collected from 250 individuals using a commercially available system (Becton Dickinson Vacutainer Systems, 
Franklin Lakes, USA). To detect S. mansoni IgG antibodies in serum samples, we used adult $S$. mansoni worm antigens $(5 \mu \mathrm{g} / \mathrm{mL})$ and performed ELISA testing according to standard procedures (Engvall \& Perlman 1971, Colley et al. 1977). The cut-off was based on the mean value of the optical density $(0.283 \pm 2$ standard deviation) associated with a negative faecal parasitological examination. Parasitological methods were employed only in individuals who were reactive in the ELISA testing.

Modified Kato-Katz method - This technique was performed using the Helm-Test ${ }^{\circledR}$ (Bio-Manguinhos, Rio de Janeiro, Brasil) kit following the protocol of Katz et al. (1972). The only modification of the procedure was to prepare three slides instead of one. Three slides were prepared from each individual. The parasite load was determined as the average number of eggs per gram (EPG) of faeces and the average EPG was calculated for the three slides (EPG $=$ sum of the number of eggs $\times 24 /$ number of slides examined), thus determining the intensity of infection with $S$. mansoni.

Saline gradient method - The device used perform this technique was previously used by Rowan and Gram (1959) and Ritchie and Berrios-Duran (1961) and was subsequently modified, to allow recovery of $S$. mansoni eggs in animal tissues. The eggs remained at the bottom of the separation column, while low-density sediments were suspended at the top through slow continuous introduction of a $3 \%$ saline solution, which created a separation gradient. Because the eggs had a higher density, they remained on the surface of the porous plate. The final sediment was then transferred to glass slides and examined under a light field microscope and the eggs were counted (Coelho et al. 2009).

Helmintex ${ }^{\circledR}$ method - A thirty grams stool sample was purified via repeated sieving using screens of different thicknesses. The obtained sediment was repeatedly subjected to the Ritchie method (described by Ritchie in 1948) until a clear supernatant was obtained that lacked a ring of debris. A solution containing paramagnetic beads was added to the resulting sediment and incubated in an orbital shaker $\left(\right.$ Phoenix ${ }^{\circledR}$ ) for $1 \mathrm{~h}$ at room temperature. Then, the microtube containing this preparation was connected to a magnet $\left(\mathrm{BioMag}^{\circledR}\right)$ for $3 \mathrm{~min}$, after which the supernatant as removed and the sediment remaining on the wall was collected and examined under a microscope to count the S. mansoni eggs (Teixeira et al. 2007).

Treatment - All patients who were positive for the presence of $S$. mansoni eggs in their stool were treated with Praziquantel ${ }^{\circledR}$ at a dose of $60 \mathrm{mg} / \mathrm{kg}$ of body weight in a single dose. The drug was administered under medical supervision at the community's public health centre.

Statistical analysis - The results were analysed using the SPSS program, version 15, using the McNemar test to assess the correlated proportions and the chi-square test to calculate $\mathrm{p}$ values.

Ethical aspects - In compliance with the ethical rules governing research on human health provided in Resolution 196/96 of the National Health Council of Brazil, this project was submitted to the Ethical Committee of the Re- search of the Department of Physiology and Pharmacology of the Federal University of Ceará (165/09). Informed written consent was obtained from the study participants or, in the case of minors, from their guardians.

\section{RESULTS}

Of the 250 individuals who provided a blood sample for ELISA testing, 118 (47.2\%) were reactive and 132 $(53.8 \%)$ were non-reactive.

Of the 118 reactive individuals, only 33 provided sufficient faecal material for all three methods under evaluation. The low number of samples of a sufficient volume received is believed to primarily be related to factors such as difficulties in defecation and embarrassment regarding the collection of stool samples and exposure of the healthcare staff to those samples, as well as a lack of interest because the subjects had already participated in previous surveys.

The average age of these patients was 30.2 years and none of the patients had clinical symptoms of the disease.

Of the 33 patients who were assessed using the Kato-Katz and the saline gradient methods, nine were positive, which included three patients who were positive based on the Kato-Katz method and six who were positive based on the saline gradient method, while only one patient was positive based on both methods. No statistically significant differences were found between the Kato-Katz and the saline gradient methods, regarding the proportion of patients diagnosed with schistosomiasis $(p=0.453)$, although the proportion of patients who were identified as positive for infection based on the saline gradient method (18.2\%) was twice the proportion of individuals determined using the Kato-Katz method (9.1\%), as shown in Table I.

The Kato-Katz method identified two patients who were positive for the parasite who were not detected using the saline gradient method, while the saline gradient method detected five patients who were positive for the infection who were not detected with the KatoKatz method.

Of the 33 patients assessed using both the Kato-Katz and Helmintex ${ }^{\circledR}$ methods, 17 were positive, including three who were positive based on the Kato-Katz method, while 14 were positive based on the Helmintex ${ }^{\circledR}$ method and two patients were detected as positive using both methods. A statistically significant difference was found between the Kato-Katz and the Helmintex ${ }^{\circledR}$ methods in the proportion of patients identified with schistosomiasis, i.e., the proportion of infected individuals identified via the Helmintex ${ }^{\circledR}$ method $(42.5 \%)$ was significantly higher $(p=0.003)$ than the proportion of infected individuals identified with the Kato-Katz method (9.1\%), as shown in Table II.

The Kato-Katz method identified one patient who was positive for the parasite who was not detected with the Helmintex ${ }^{\circledR}$ method, while the Helmintex ${ }^{\circledR}$ method identified 12 infected patients who were not detected when using the Kato-Katz method.

Of the 33 patients assessed with both the saline gradient and the Helmintex ${ }^{\circledR}$ methods, 20 were positive, of whom six were positive for the parasite based on the saline gradient method, while 14 were positive based on the Helmintex ${ }^{\circledR}$ method and four patients were identified 
as positive for the infection using both methods. A statistically significant difference was found between the Helmintex ${ }^{\circledR}$ and the saline gradient methods in the proportion of patients diagnosed with schistosomiasis, i.e., the proportion of infected individuals identified with the Helmintex ${ }^{\circledR}$ method $(42.4 \%)$ was significantly higher ( $=0.039$ ) than the proportion of infected individuals identified when using the saline gradient method $(18.2 \%)$, as shown in Table III.

The saline gradient method detected two infected patients who were not detected with the Helmintex ${ }^{\circledR}$ method, while the Helmintex ${ }^{\circledR}$ method detected 10 patients who were positive for the parasite who were not detected with the saline gradient method.

The parasite loads found using the evaluated methods were 8.0 EPG for the Kato-Katz, 5.4 EPG for the saline gradient and 1.1 EPG for the Helminte ${ }^{\circledR}$ methods.

\section{DISCUSSION}

Previous studies have described strategies for defining the goals of infectious disease control in developing countries by governmental and international agencies in collaboration with the World Health Organization. Considerable progress has been made in this arena, but there has been a tendency to emphasise treatment and prevention through the use of vaccines, neglecting the importance of good diagnostic tests (Ridley 2006).

When the Kato-Katz technique is the only type of test used to diagnose schistosomiasis, the true prevalence of the disease is underestimated due to the low efficiency of this methodology in detecting cases involving a low number of eggs (Engels et al. 1996). The ability to preselect individuals to be subjected to parasitological stool examination through the use of a serological techniques that are proven to be more sensitive enables the confirmation of infection and, thus, improves the accuracy of the determined prevalence rate (Gargione et al. 2008).

The strategy currently used in Brazil to diagnose schistosomiasis mansoni, is the Kato-Katz technique with one sample and one slide being used to determine the rate of infection, which does not result in a sufficiently high sensitivity to obtain correct diagnosis; consequently, the prevalence of schistosomiasis mansoni in low endemic areas is underestimated. Given the lack of sensitivity of this method in areas where there is a low parasite load and low endemicity, researchers have pursued alternative diagnostic strategies aimed at overcoming this limitation (Enk et al. 2008, Siqueira et al. 2011).

Using the Kato-Katz parasitological method, out of the 33 samples analysed, three $S$. mansoni positive samples were detected $(9.1 \%)$, all of which exhibited one egg per slide. It is noteworthy that if we had performed the reading using only one slide, as is routinely performed in schistosomiasis mansoni control programs, only one individual would have tested positive.

Among 33 samples analysed, we found that the proportion of infected individuals detected with the KatoKatz method was $9.1 \%$, while the saline gradient method resulted in a detection proportion of $18.2 \%$. Thus, the saline gradient method detected a greater number of infected cases than the Kato-Katz method in both studies.
According to Coelho et al. (2009), the saline gradient method has the following advantages: it requires only water and sodium chloride the device employed to perform sedimentation can be re-used as many times as necessary, is allows quick reading of the sediment produced (in approximately $20 \mathrm{~min}$ ), it provides the ability to process 20 samples at once and the obtained sediments can be stored for up to 60 days for further reading.

\section{TABLE I}

Comparison between the Kato-Katz and salinity gradient methods in the detection of schistosomiasis mansoni in low endemic setting

\begin{tabular}{|c|c|c|c|}
\hline \multirow[b]{2}{*}{ Saline gradient } & \multicolumn{2}{|c|}{$\begin{array}{c}\text { Kato-Katz } \\
\text { n (\%) }\end{array}$} & \multirow{2}{*}{$\begin{array}{l}\text { Total } \\
\text { n }(\%)\end{array}$} \\
\hline & Positive & Negative & \\
\hline Positive & $1(3)$ & $5(15.2)$ & $6(18.2)$ \\
\hline Negative & $2(6.1)$ & $25(75.7)$ & $27(81.8)$ \\
\hline Total & $3(9.1)$ & $30(90.9)$ & $33(100)$ \\
\hline
\end{tabular}

data analyzed by the McNemar test.

\section{TABLE II}

Comparison between the Kato-Katz and Helmintex ${ }^{\circledR}$ methods in the detection of schistosomiasis mansoni in low endemic setting

\begin{tabular}{lccc}
\hline & \multicolumn{2}{c}{ Kato-Katz } \\
& \multicolumn{2}{c}{$\mathrm{n}(\%)$} & \\
\cline { 2 - 3 } Helmintex $^{\circledR}$ & Positive & Negative & $\begin{array}{c}\text { Total } \\
\text { n }(\%)\end{array}$ \\
\hline Positive & $2(6.1)$ & $12(36.4)$ & $14(42.5)$ \\
Negative & $1(3)$ & $18(54.5)$ & $19(57.5)$ \\
\hline Total & $3(9.1)$ & $30(90.9)$ & $33(100)$ \\
\hline
\end{tabular}

data analyzed by the McNemar test.

TABLE III

Comparison between the salinity gradient and Helmintex ${ }^{\circledR}$ methods in the detection of schistosomiasis mansoni in low endemic setting

\begin{tabular}{lccc}
\hline & \multicolumn{3}{c}{$\begin{array}{c}\text { Saline gradient } \\
\mathrm{n}(\%)\end{array}$} \\
\cline { 2 - 3 } Helmintex $^{\circledR}$ & Positive & Negative & $\begin{array}{c}\text { Total } \\
\mathrm{n}(\%)\end{array}$ \\
\hline Positive & $4(12.1)$ & $10(30.3)$ & $14(42.4)$ \\
Negative & $2(6.1)$ & $17(51.5)$ & $19(57.6)$ \\
\hline Total & $6(18.2)$ & $27(81.8)$ & $33(100)$ \\
\hline
\end{tabular}

data analyzed by the McNemar test. 
Regarding the comparison of the Kato-Katz and Helmintex $^{\circledR}$ methods, 15 of the 33 samples were found to be positive for the parasite $(45.5 \%)$ by one of these two methods; however, 12 (36.4\%) of these individuals were diagnosed only with the Helminte ${ }^{\circledR}$ method. Thus, this method was shown to be more effective in detecting infected cases in the locality being studied. Additionally, when we compared the saline gradient method with the Helmintex ${ }^{\circledR}$ method, 16 of the 33 individuals (48.5\%) were positive by one of these two techniques, although $10(30.3 \%)$ of these were positive only under the Helmintex ${ }^{\circledR}$ testing, demonstrating that the latter method was more effective in detecting cases in the study area.

When we subjected 33 stool samples to the Helmintex $^{\circledR}$ technique, we found that $42.4 \%$ of the samples were a positive, which was the highest rate observed in this study. We suggest the use of this method in epidemiological investigations for subsequent comparisons, as we were the first to apply it in the field.

However, there are several considerations that should be noted regarding our experience in the implementation of the Helmintex ${ }^{\circledR}$ method. Due to the large amount of stool required during the sedimentation phase $(30 \mathrm{~g})$, the sample requires five washes on average to obtain a clear supernatant, making this technique very time consuming. In the second step of the method, the material was sieved through different screens which should be washed after each use, creating a risk of contamination between samples if washing of these screens is not conducted carefully. To eliminate this risk, the development of disposable screens would be advantageous.

Among the new parasitological techniques assessed in this study, the saline gradient method was shown to be more effective in detecting carriers of schistosomiasis in a low endemic area than the Kato-Katz method. However, the Helmintex ${ }^{\circledR}$ technique was shown to be more effective than both the Kato-Katz and the saline gradient methods, though some cases were missed by all three methods. Although the search for new methods is essential to develop better diagnostic approaches and, thus, contribute to public health by providing a more realistic view of the schistosomiasis situation, the use of more than one diagnostic technique will always provide better detection of cases, particularly in of low endemicity areas. However, in areas of low resources where repeated Kato-Katz examinations continue to be an option for control programs (da Frota et al. 2011), it is essential to combine the various methods available to most accurately determine the number of cases of this disease.

\section{ACKNOWLEDGEMENTS}

To the Laboratory of Schistosomiasis in Minas Gerais by FIOCRUZ training and supply of materials needed for the technique of the saline gradient, to Prof Dr Carlos GraeffTeixeira, Laboratory of Molecular Parasitology, PUCRS, for providing the kits Helmintex ${ }^{\circledR}$, the Health Secretariat of the state of Ceará, for providing the kits for Kato-Katz, and Health Secretariat of the city of Maranguape, for the support in the field work.

\section{REFERENCES}

Coelho PMZ, Jurberg AD, Oliveira AA, Katz N 2009. Use of a saline gradient for the diagnosis of schistosomiasis. Mem Inst Oswaldo Cruz 104: 720-723.

Colley DG, Hieny SE, Bartholomew RK, Cook JA 1977. Immune response during human schistosomiasis mansoni: regulatory effect of patient sera on human lymphocytes blastogenic responses to schistosomal antigen preparations. Am J Trop Med Hyg 26: 917-925.

da Frota SM, Carneiro TR, Queiroz JAN, Alencar LM, Heukelbach J, Bezerra FSM 2011. Combination of Kato-Katz faecal examinations and ELISA to improve accuracy of diagnosis of intestinal schistosomiasis in a low-endemic setting in Brazil. Acta Trop 120 (Suppl. 1): S138-S141.

Engels D, Sinzinkayo E, Gryseels B 1996. Day-to-day egg count fluctuation in Schistosoma mansoni infection and its operational implications. Am J Trop Med Hyg 54: 319-324.

Engvall E, Perlman P 1971. Enzyme-linked immunosorbent assay (ELISA) quantitative assay of immunoglobulin G. Immunochemistry 8: 871-874.

Enk MJ, Lima ACL, Drummond SC, Schall VT, Coelho PMZ 2008. The effect of the number of stool samples on the observed prevalence and the infection intensity with Schistosoma mansoni among a population in an area of low transmission. Acta Trop 108: 222-228.

Gargioni C, Da Silva RM, Thomé CM, Quadros CM da S, Kanamura HY 2008. Utilização de método sorológico como ferramenta diagnóstica para implementação da vigilância e controle da esquistossomose no município de Holambra, São Paulo, Brasil. Cad Saude Publica 24: 373-379.

Katz N, Chaves A, Pellegrino JP 1972. A simple device for quantitative stool thick-smear technique in schistosomiasis mansoni. Rev Inst Med Trop Sao Paulo 14: 397-400.

Oliveira EJ, Kanamura YH, Dias LC de S, Soares LCB, Lima DMC, Ciaravolho RM de C 2003. Elisa-IgM para diagnósticos da esquistossomose mansônica em área de baixa endemicidade. Cad Saude Publica 19: 255-261.

Rabello A, Pontes LA, Enk MJ, Montenegro SML, Morais CNL 2008. Diagnóstico parasitológico, imunológico e molecular da esquistossomose mansoni. In OS Carvalho, PMZ Coelho, HL Lenzi (org.), Schistosoma mansoni e equistossomose: uma visão multidisciplinar, Fiocruz, Rio de Janeiro, p. 897-925.

Ridley RG 2006. Diagnostics take centre stage. Nat Rev Microbiol 4 (Suppl. 9): S1.

Ritchie LS 1948. An ether sedimentation technique for routine stool examinations. Bull U S Army Med Dep 8: 326.

Ritchie LS, Berrios-Duran LA 1961. A simple procedure for recovering schistosome eggs in mass from tissues. J Parasitol 47: 363-365.

Rowan WB, Gram AL 1959. Quantitative recovery of helminth eggs from relatively large samples of feces and sewage. J Parasitol 45: 615-621.

Siqueira LMV, Coelho PMZ, de Oliveira AA, Massara CL, Carneiro NFF, Lima ACL, Enk MJ 2011. Evaluation of two coproscopic techniques for the diagnosis of schistosomiasis in a low-transmission area in the state of Minas Gerais, Brazil. Mem Inst Oswaldo Cruz 106: 844-850.

Teixeira CF, Neuhauss E, Bem R, Romanzini J, Graeff-Teixeira C 2007. Detection of Schistosoma mansoni eggs in feces through their interaction with paramagnetic beads in a magnetic field. PLoS Negl Trop Dis 1: e73.

WHO - World Health Organization 2008. The social context of schistosomiasis and its control: an introduction and annotated bibliography, WHO, Geneva, $213 \mathrm{pp}$. 